\title{
Article \\ Study of Temperature Field Distribution in Topographic Bias Tunnel Based on Monitoring Data
}

\author{
Tao Zhang, Lei Nie, Min Zhang *, Shulin Dai, Yan Xu, Chao Du, Xiangjian Rui, Yuanyuan He and Yuzheng Wang \\ College of Construction Engineering, Jilin University, Changchun 130021, China; \\ zhangtao18@mails.jlu.edu.cn (T.Z.); nielei@jlu.edu.cn (L.N.); daisl@jlu.edu.cn (S.D.); xuyan8102@jlu.edu.cn (Y.X.); \\ duchao18@mails.jlu.edu.cn (C.D.); ruixj19@mails.jlu.edu.cn (X.R.); hyy20@mails.jlu.edu.cn (Y.H.); \\ yuzhengw18@mails.jlu.edu.cn (Y.W.) \\ * Correspondence: minzhang@jlu.edu.cn
}

Citation: Zhang, T.; Nie, L.; Zhang, M.; Dai, S.; Xu, Y.; Du, C.; Rui, X.; He, Y.; Wang, Y. Study of Temperature Field Distribution in Topographic Bias Tunnel Based on Monitoring Data. Symmetry 2021, 13, 1492. https://doi.org/10.3390/sym13081492

Academic Editors: Elżbieta Szafranko, Piotr E. Srokosz and Jana Korytarova

Received: 19 July 2021

Accepted: 12 August 2021

Published: 13 August 2021

Publisher's Note: MDPI stays neutral with regard to jurisdictional claims in published maps and institutional affiliations.

Copyright: (c) 2021 by the authors. Licensee MDPI, Basel, Switzerland. This article is an open access article distributed under the terms and conditions of the Creative Commons Attribution (CC BY) license (https:// creativecommons.org/licenses/by/ $4.0 /)$.

\begin{abstract}
In recent decades, numerous tunnels have been built in the cold region of China. However, the temperature field of topographically biased tunnels in the monsoon freeze zone has not been sufficiently studied. In this study, we monitored the temperature of the surrounding rock in two topographic bias sections of the Huitougou Tunnel and analyzed the results by fitting them to the monitoring results. The results showed that the temperature of the surrounding rock on both sides after tunnel excavation varied periodically in an approximate triangular function. As the distance from the cave wall increased, the annual average temperature of the surrounding rock did not change significantly, the amplitude decreased, and the delay time increased, while the annual maximum temperature decreased, and the annual minimum temperature increased. The heat generated by blasting, the heat of hydration of the primary and secondary lining, and the decorated concrete all caused a significant increase in the temperature of the surrounding rock within $4 \mathrm{~m}$ for a short period of time. Both construction and topographic factors led to asymmetry in the distribution of the surrounding rock temperature in different ways. The results of this paper are intended as a reference for other studies on temperature in deviated tunnels.
\end{abstract}

Keywords: topographic bias tunnel; surrounding rock temperature; asymmetric temperature; field monitoring; frozen depth

\section{Introduction}

With the rapid growth of China's economy, the number and total length of the tunnels constructed in China have increased dramatically [1]. However, there are many problems related to the construction and operation of tunnels, and the study of tunnel temperature field has been the focus of many scientists and engineers [2-5]. The temperature field of tunnels in cold zones has been the focus of research because tunnel frost damage problems easily occur, such as lining concrete damage, cracking and peeling, leakage, icicles, and pavement icing [6-8].

Currently, research on tunnel temperature fields is mainly conducted through field monitoring, theoretical calculations, numerical simulations, and model experiments [9-11]. He et al. [12] monitored the temperature and humidity in a sub-sea tunnel. Jun et al. monitored the temperature of the air, road surface, lining surface, and other locations in 104 tunnels [13]. As for theoretical calculations, Zhang et al. [14] proposed a two-dimensional unsteady heat transfer formalism based on Green's function method (GFM) and finite element method (FEM) to consider the realities in underground tunnels. Lyu et al. established an analytical solution of frost heaving force and stress distribution in cold region tunnels under non-axisymmetric stress and transversely isotropic frost heave of surrounding rock [15]. For numerical simulations, Zhang et al. [16] conducted a three-dimensional simulation of the temperature field in the cold region. Tan et al. studied the temperature field change pattern and insulation measures in the Tibetan Galungla Tunnel's surrounding rock under ventilation conditions [17]. In terms of 
physical modeling, Zhang et al. investigated the effect of construction temperature disturbance and boundary temperature disturbance on the temperature distribution in the permafrost tunnel envelope by developing a physical model [18]. Zeng et al. investigated the coupling effect of convective conduction and low inlet temperature airflow by similar simulation model tests [19].

However, researchers have mostly conducted longitudinal temperature distributions in tunnels with flat ground surfaces, but there is a lack of in-depth research on the temperature distribution in the transverse section of tunnels. When the surface of the tunnel section is inclined, the temperature field of shallow buried bias tunnels located in cold regions are not symmetrically distributed along the tunnel axis. Therefore, it is of great relevance to study the distribution of temperature field in this special type of tunnel and to determine the distribution range of freezing depth for the prevention and control of frost damage in this type of tunnel in China's seasonal freezing zone.

In this paper, long-term temperature monitoring was conducted for both deep and shallow buried biased tunnel cross-sections in the Huitougou Tunnel. By setting two sets of symmetrical measurement lines on the cross-section, the temperature variation pattern of the tunnel in the short- and long-term after tunnel excavation was examined. The temperature change curves at the monitoring points were fitted by trigonometric functions, and the distribution patterns of the surrounding rock temperature and the annual minimum and maximum temperatures over distances were investigated. The asymmetry of the temperature field in the topographic deviated tunnel was analyzed, for which an explanation was also given. This paper completes the study of the distribution of temperature fields in topographic bias tunnels in cold regions and offers guidance for the freeze protection of such tunnels.

\section{Engineering Geological Conditions}

The Huitougou Tunnel is part of the He-Da Expressway. The tunnel entrance is $829 \mathrm{~m}$ above sea level. Due to the restrictions on route selection and topography, the tunnel runs through the sloped terrain near the entrance. This tunnel involves building two separate tunnels [17]. The left tunnel is $720 \mathrm{~m}$ long (from LK315 + 655 to LK316 + 375), and the right tunnel is $660 \mathrm{~m}$ long (from RK315 + 680 to RK316 + 340).

As illustrated in Figure 1a, Section $1(\mathrm{LK} 316+260)$ is buried at a depth of $40.83 \mathrm{~m}$, and the surface slope is approximately $15^{\circ}$. The stratum crossed by the section is mediumweathering granite gneiss. There are joints and cracks in the rocks, and the structure is fractured. Drill hole data show that the angle of joints and fissures is mainly $60^{\circ}$. According to the survey data, the longitudinal wave speed of granite gneiss is from 4789 to $5139 \mathrm{~m} / \mathrm{s}$, and the uniaxial compressive strength $R c=42.41 \mathrm{Mpa}$. According to the Chinese Code for the Design of Road Tunnels, the surrounding rock is classified as Class IV. Groundwater is mainly fissure water. The survey work found that relatively soft gneisses 1-2 $\mathrm{m}$ thick were locally trapped in the area near the cross-section.

The tunnel excavation profile is $9.58 \mathrm{~m}$ high and $12.36 \mathrm{~m}$ wide. As shown in Figure $1 \mathrm{~b}$, the initial lining of the tunnel is in the form of anchors, lattice steel arch, and shotcrete. The anchor rod is $\Phi 22$ grouted anchor bolts, $3.5 \mathrm{~m}$ long. The sprayed concrete is $21 \mathrm{~cm}$ thick, and the second lining concrete is $40 \mathrm{~cm}$. The tunnel was excavated using step method.

As illustrated in Figure 2a, Section $2($ RK $315+710)$ is buried at a depth of $14.49 \mathrm{~m}$, and the surface slope is approximately $21^{\circ}$. The stratum crossed by the section is strongly weathered gneiss. The rock is more broken in a fractured structure and locally in a bulk structure. The longitudinal wave speed of rock is $1573 \mathrm{~m} / \mathrm{s}$. According to the Chinese Code for the Design of Road Tunnels, the surrounding rock is classified as Class V. Groundwater is mainly fissure water. Similarly, there are no discontinuous geotechnical bodies such as faults in the vicinity of this section. 


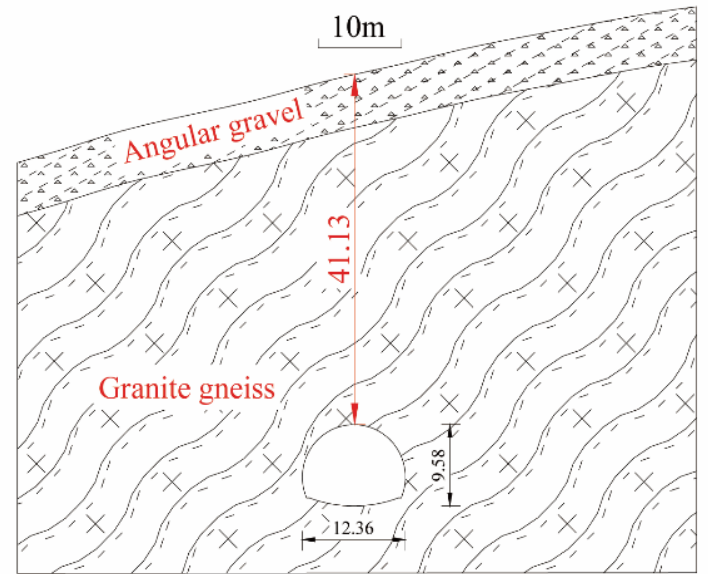

(a)

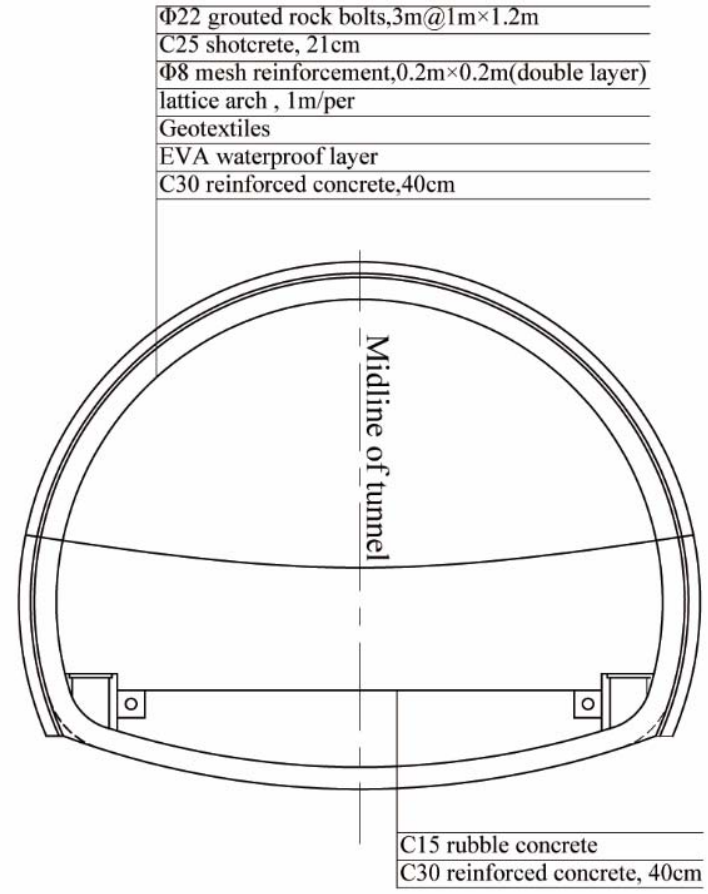

(b)

Figure 1. Section 1 (LK316 + 260) (unit: m): (a) cross-section of the monitoring section; (b) excavation method and support structure.

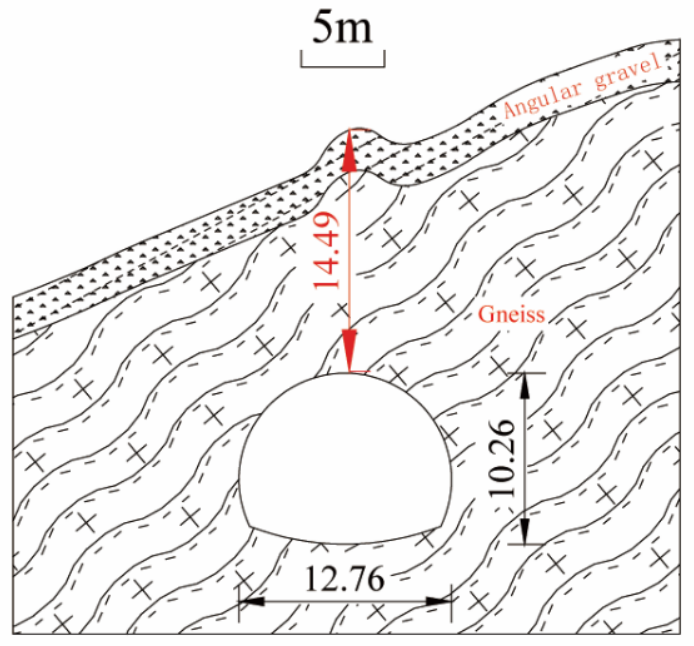

(a)

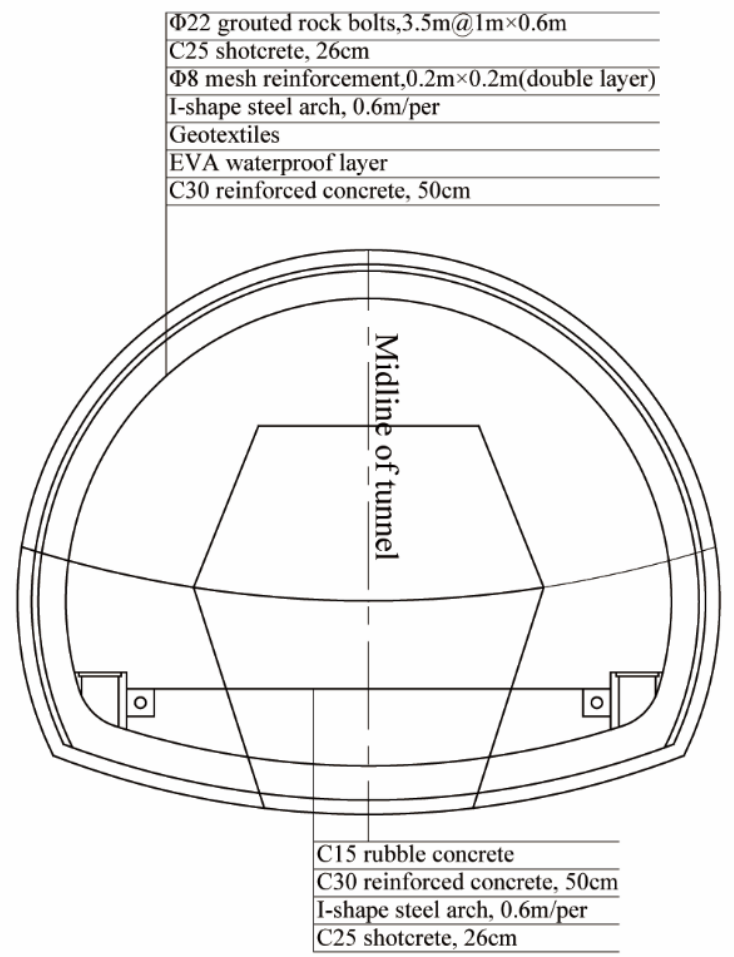

(b)

Figure 2. Section 2 (RK315 + 710) (unit: m): (a) cross-section of monitoring section; (b) excavation method and support structure. 
The tunnel excavation profile is $10.26 \mathrm{~m}$ high and $12.76 \mathrm{~m}$ wide. As shown in Figure $2 \mathrm{~b}$, the initial lining of the tunnel is in the form of anchor rod, steel arch, and shotcrete. The anchor rod is $\Phi 22$ grouted anchor rod, $3.5 \mathrm{~m}$ long. The sprayed concrete is $26 \mathrm{~cm}$ thick, and the second lining concrete is $50 \mathrm{~cm}$ thick. The tunnel was excavated in a circular pattern to reserve the core soil.

\section{Monitoring Arrangement and Results}

\subsection{Monitoring Arrangement}

The temperature sensor was provided by Changsha Yituo Civil Engineering Monitoring Instruments Co. As shown in Figure 3a, the thermometer model was YT-BD-0101, the accuracy was $0.5^{\circ} \mathrm{C}$, the measurement range was $-40 / 125^{\circ} \mathrm{C}$, and it had a waterproof treatment. The installation was pre-buried by drilling, i.e., drilling holes at the observation site, burying the thermometer at the specified depth, and then pouring with the concrete. Temperature sensors were manually read using a readout.

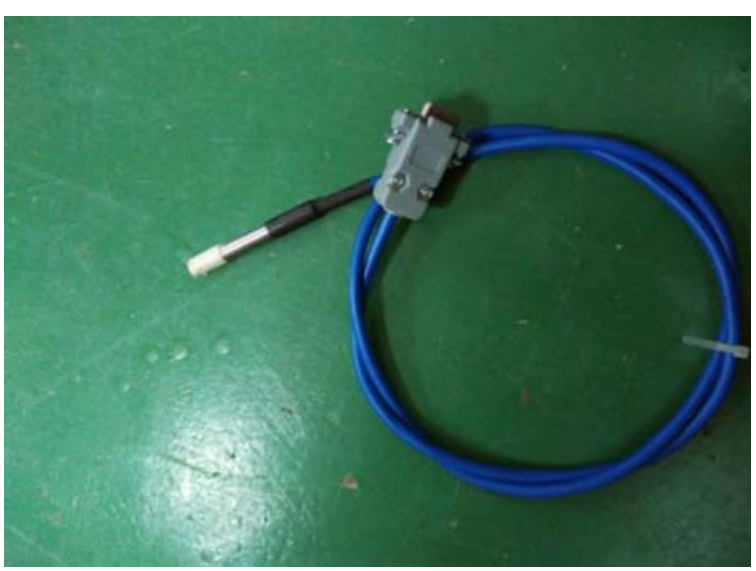

(a)

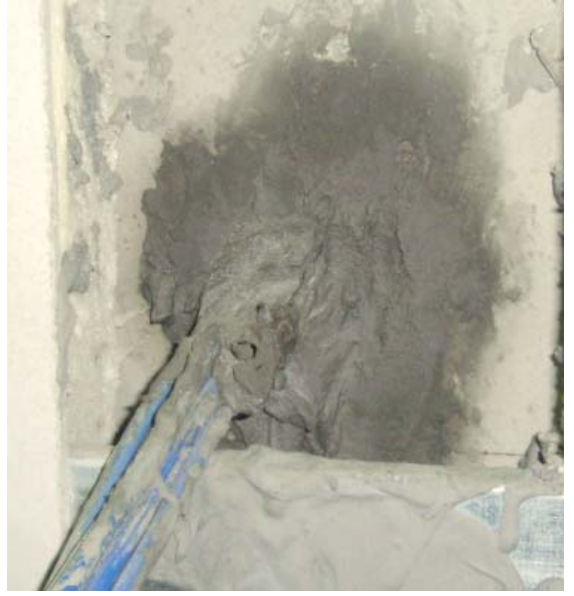

(b)

Figure 3. Temperature sensor: (a) substance; (b) on-site installation.

Figure 4a shows the layout of the measurement lines and the location of the temperature sensors installed in Section 1. Four measurement lines were symmetrically installed about the tunnel centerline. As depicted in Figure $4 \mathrm{~b}$, monitoring point 1-3 was $0.4 \mathrm{~m}$ away from the tunnel wall, monitoring point 1-2 was $2 \mathrm{~m}$ away from the tunnel wall, and the deepest monitoring point 1-1 was $3.7 \mathrm{~m}$ away from the tunnel wall. Temperature sensors on other measurement lines were also attached in accordance with this rule.

The layout of the measurement line and the temperature sensor installation positions in Section 2 are presented in Figure 5a. The positions of the measurement lines were symmetrically installed about the tunnel centerline. Figure $5 \mathrm{~b}$ reveals that the temperature sensor installation position in Section 2 was distinct from that of Section 1. On the ML-III measuring line, the monitoring point 2-1 was $1 \mathrm{~m}$ away from the tunnel wall, 2-2 was $2.5 \mathrm{~m}$ away from the tunnel wall, and 2-3 was $4 \mathrm{~m}$ away from the tunnel wall. The same was applied to the other measuring lines. The deepest temperature sensor on the ML-III measuring line was damaged during installation and backfilling of the concrete; thus, it was not plotted in the figure. 


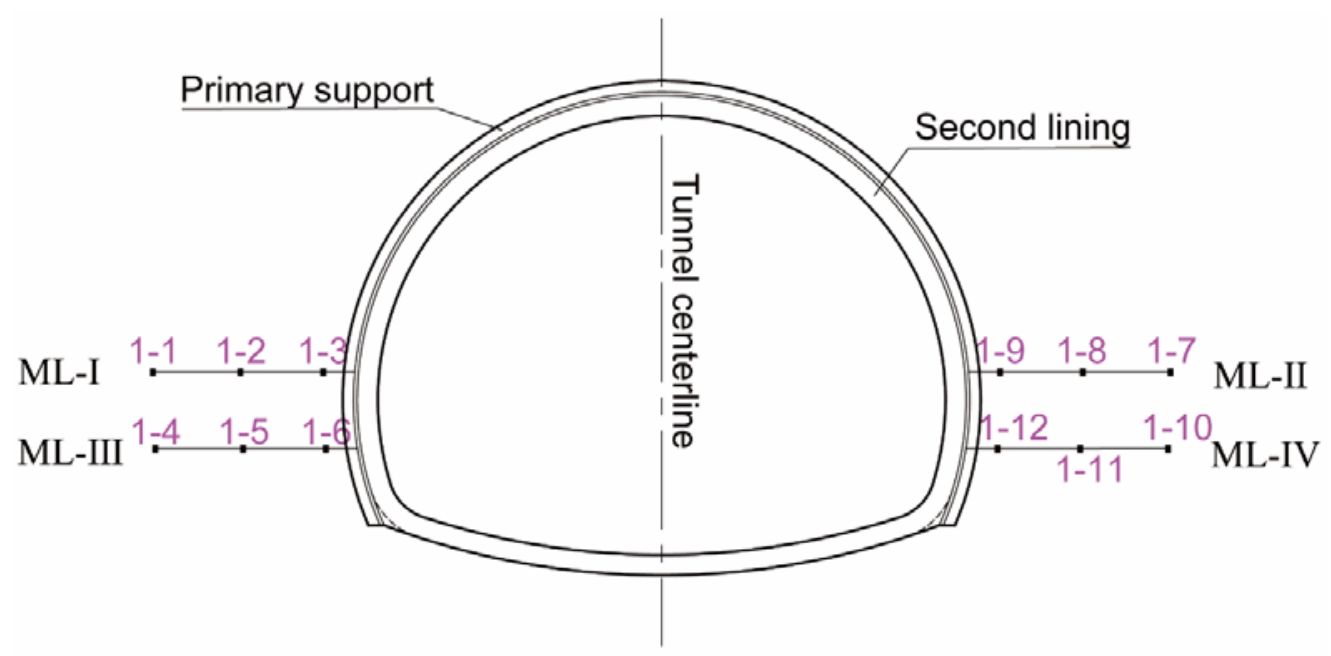

(a)

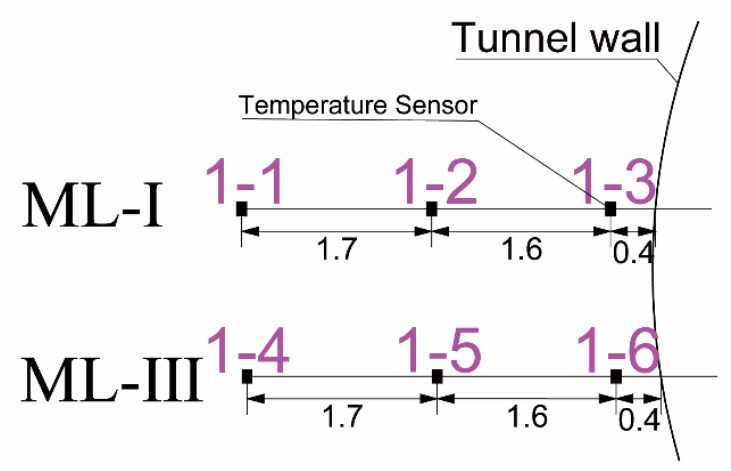

(b)

Figure 4. Monitoring arrangement of Section 1: (a) location; (b) details (unit: m).

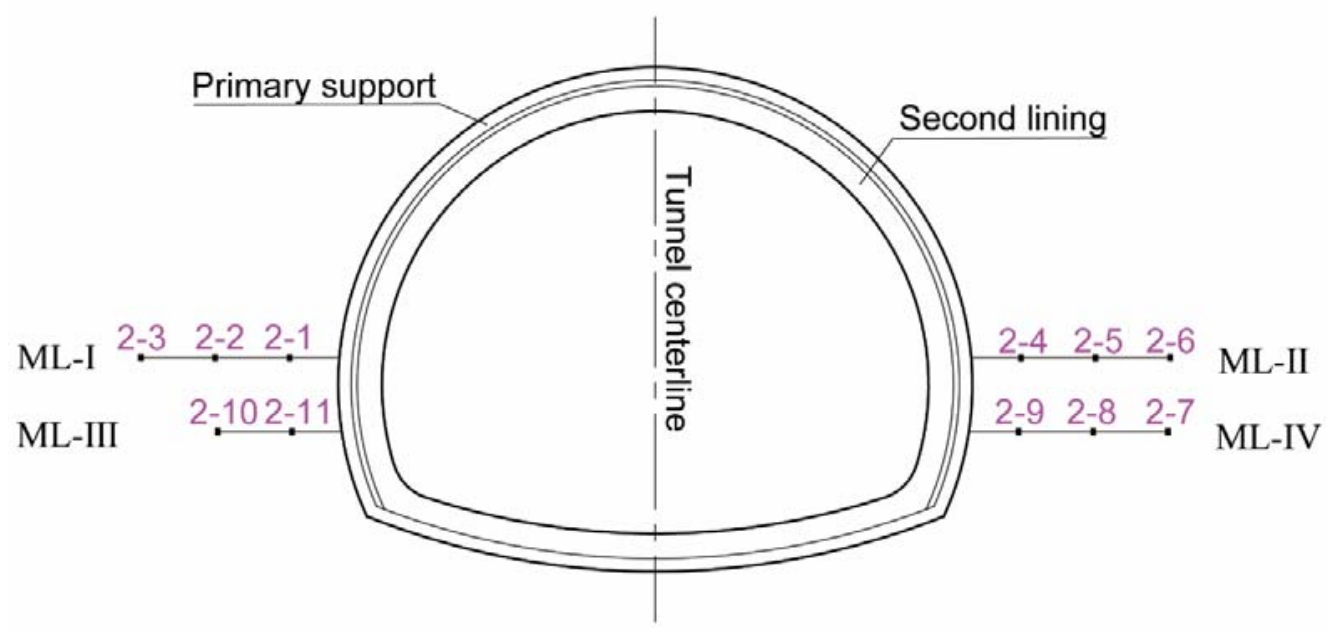

(a)

Figure 5. Cont. 


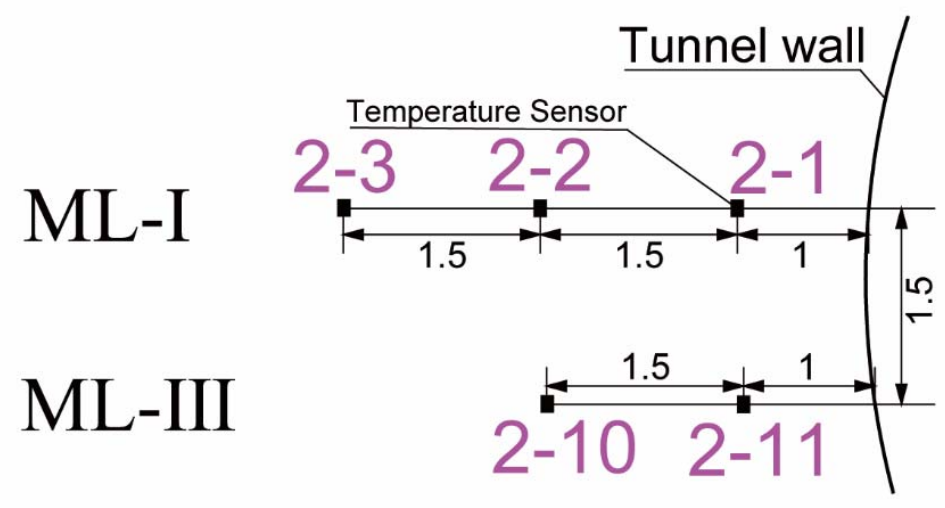

(b)

Figure 5. Monitoring arrangement of Section 2: (a) location; (b) details (unit: m).

The installation of the temperature sensors in both sections was conducted at a similar time due to the arrival date of the tunnel monitoring instruments. Due to this, the excavation statuses of the two sections were different when the monitoring instruments were installed. All monitoring points for the full section were installed after the lower step excavation and started working after the construction of the second lining at section LK316 + 260. For section RK315 + 710, sensors numbered 1 to 6 were installed after the excavation of the upper step, and sensors numbered 7 to 10 were installed after the excavation of the lower step. The monitoring period was 14 months, from May 2015 to June 2016.

\subsection{Monitoring Results of Section 1 (Section LK316 + 260)}

\subsubsection{Patterns of Temperature Change in the Short-Term}

As the temperature trends in the surrounding rock were essentially the same in the short-term, we present only the temperature results for one measurement line in Figure 6. As shown in Figure 6, the temperature of the perimeter rock at different depths increased with time due to the general increase in external air temperatures during the period from May to August. As the second lining of the section was completed by the time the monitoring device was installed, the temperature of the surrounding rock varied moderately from outside to inside. The temperature of the monitoring point closest to the wall fluctuated with the change in temperature outside the tunnel wall.

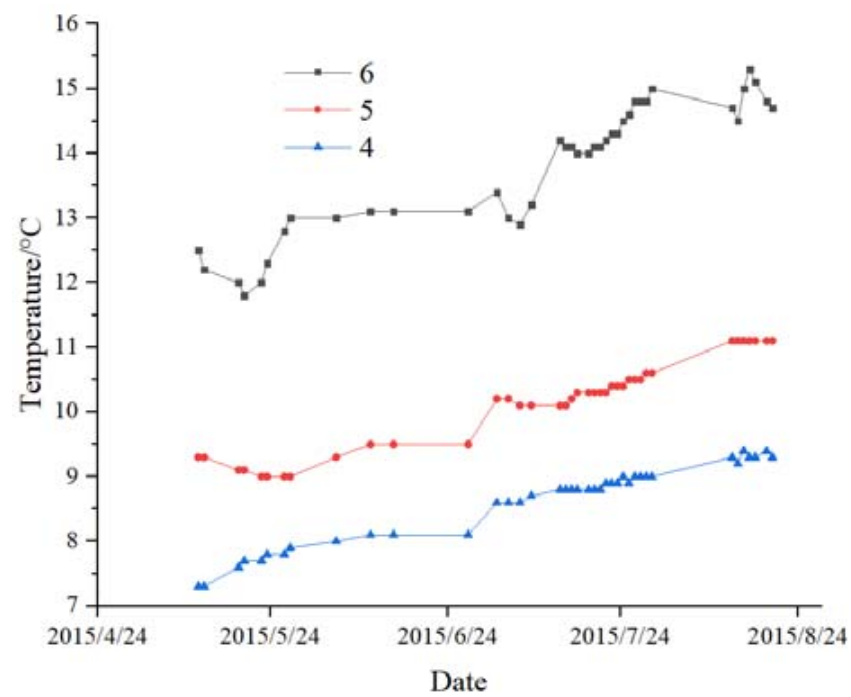

Figure 6. Short-term temperature change. 


\subsubsection{Temperature Change in the Long-Term}

\section{(1) Fitting equation}

In previous studies, the annual period sine function has been widely used to fit temperature data. We used Equation (1) adopted by [20-22] to determine the annual temperature variation of the tunnel envelope.

$$
T=T_{m}+T_{a} \sin \left[\frac{2 \pi}{T_{1}}\left(t-t_{c}\right)\right]
$$

where $t$ is time and $T_{a}$ is the annual temperature amplitude $\left({ }^{\circ} \mathrm{C}\right) . T_{1}$ is one year and was taken as 12 months in this paper, i.e., fixed at $T_{1}=12$. $T_{m}$ is the average temperature in one year $\left({ }^{\circ} \mathrm{C}\right) ; t_{c}$ is the phase difference, which is consistent with the unit of $t$.

In this paper, we fitted the monthly average temperature curve with time at the monitoring sites by custom trigonometric functions with Origin software according to Equation (1). The fitted equations were used to derive the corresponding parameters to study the temporal and spatial variation in the surrounding rock temperature.

\section{(2) Temperature variation}

Figure 7 plots the variations in temperature by month for each monitoring point in this tunnel section. The monthly temperature curve of the tunnel surrounding the rock temperature monitoring point was roughly sinusoidal. According to Equation (1), the data were fitted to the points. The obtained equation and correlation coefficient $R^{2}$ are both listed in Figure 7. The $\mathrm{R}^{2}$ was greater than 0.7, indicating that the temperature fitting degree of each monitoring point was also relatively good.

As illustrated in Figure 7, the annual maximum temperature of the surrounding rock decreased, but the annual minimum temperature increased as the distance from the tunnel wall increased. Synchronously, the temperature amplitude of the surrounding rock decreased and the peaks and troughs at the rock monitoring points appeared later.

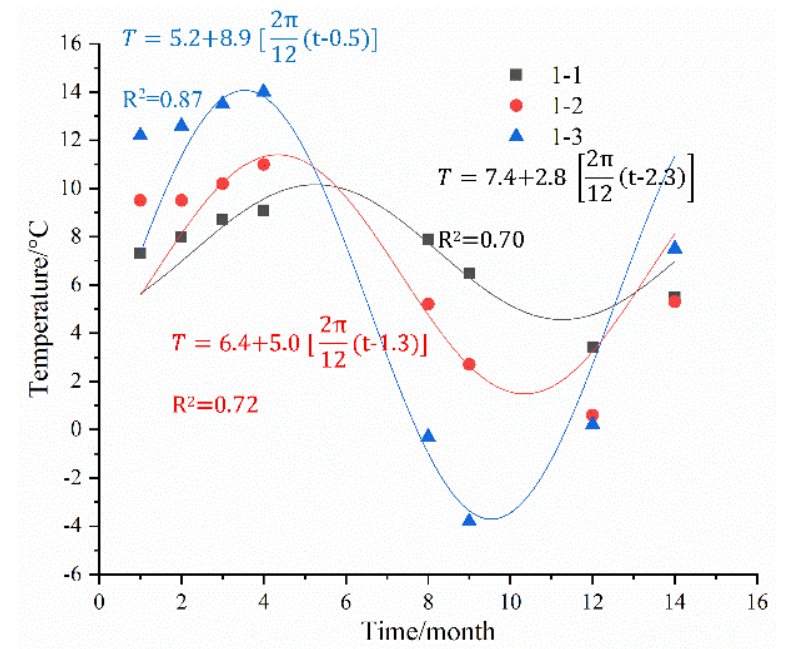

(a)

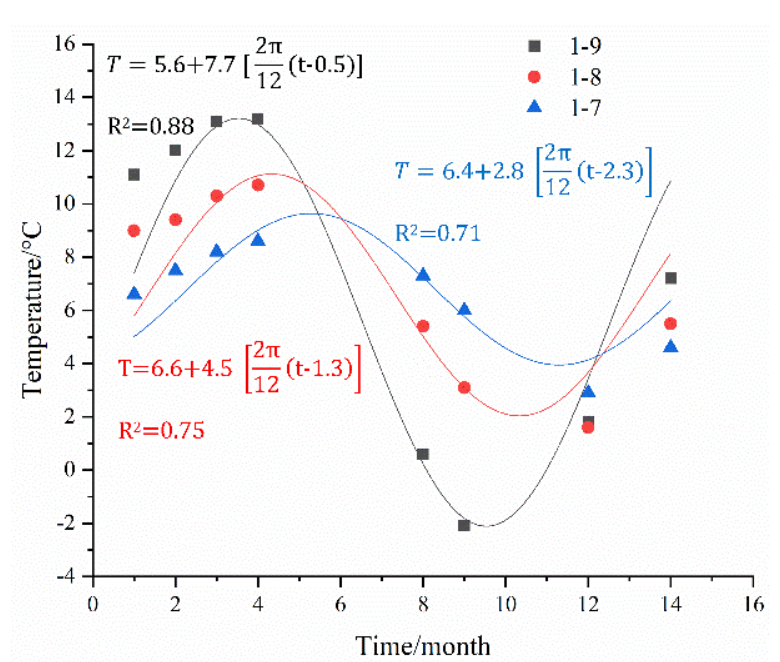

(b)

Figure 7. Cont. 


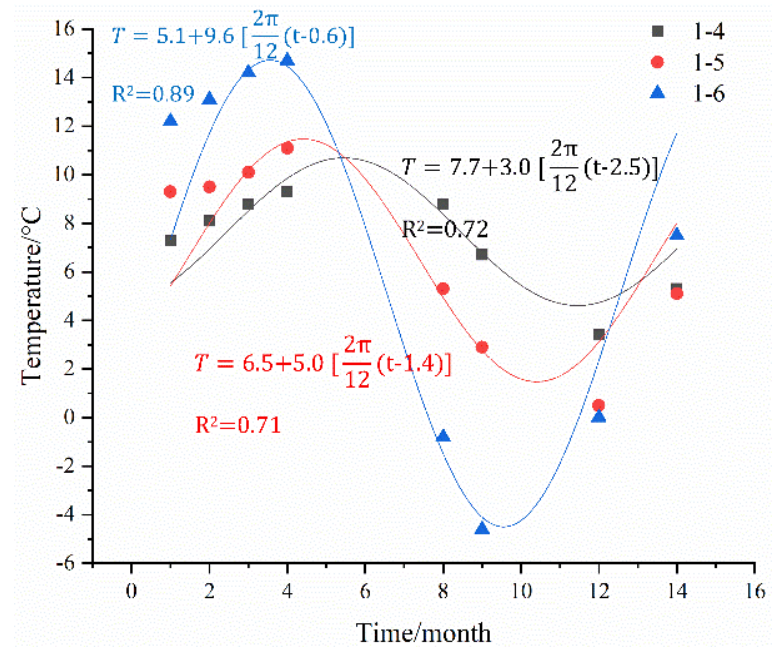

(c)

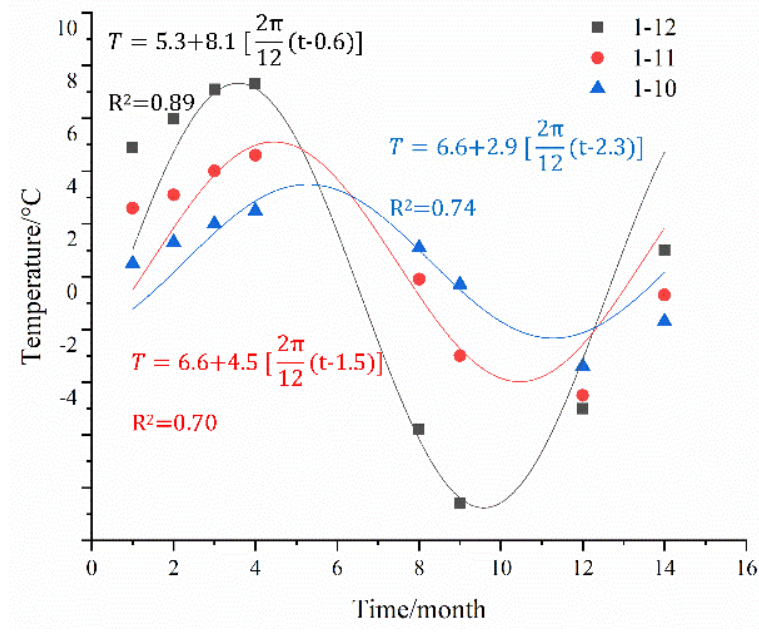

(d)

Figure 7. Monthly average temperature curves of each monitoring point of the RK316 + 260 section: (a) ML-I; (b) ML-II; (c) ML-III; and (d) ML-IV.

The inflow of air after tunnel excavation was the main reason for the change in the temperature field of the surrounding rocks inside the mountain. As the distance from the tunnel opening increased, the temperature inside the tunnel became less affected by fluctuations in the external air temperature, and equally, the temperature of the tunnel envelope was less affected.

Since the parameters adopted by the fitting equation each represent several characteristics, we separately describe the parameters of the fitting equation. Figure 8 describes the relationship between the parameters of the fitting equation of each monitoring point and the distance from the tunnel wall. In general, the pattern of the coefficient variation was approximately consistent across the four measuring lines. As the distance from the tunnel wall increased, the mean annual temperature $T_{m}$ increased; the annual temperature amplitude $T_{a}$ decreased, and the phase difference $t_{c}$ increased.

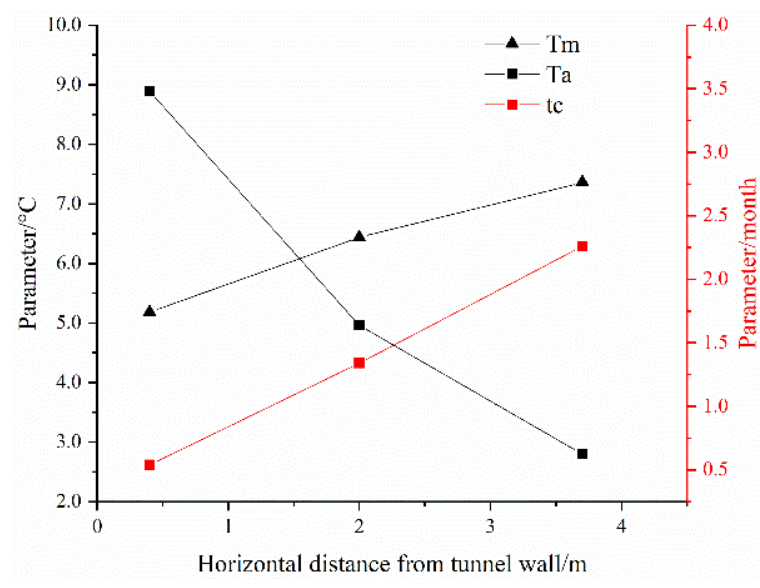

(a)

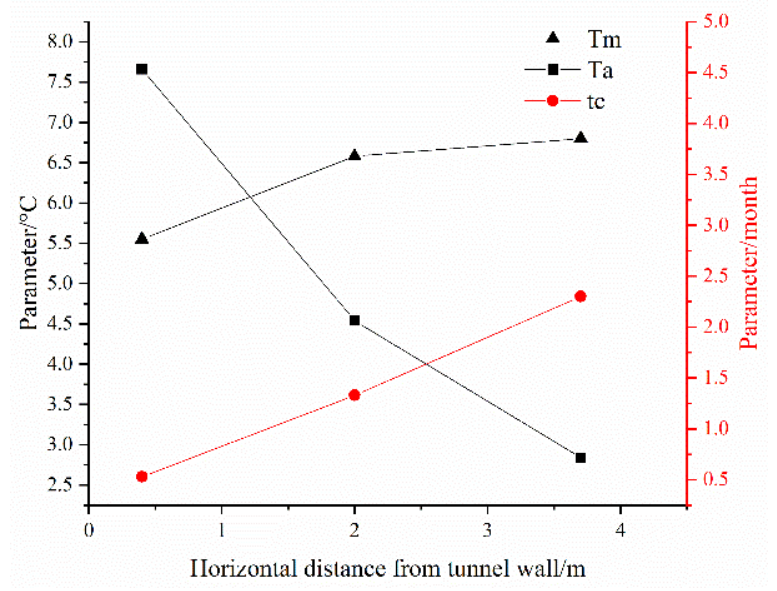

(b)

Figure 8. Cont. 


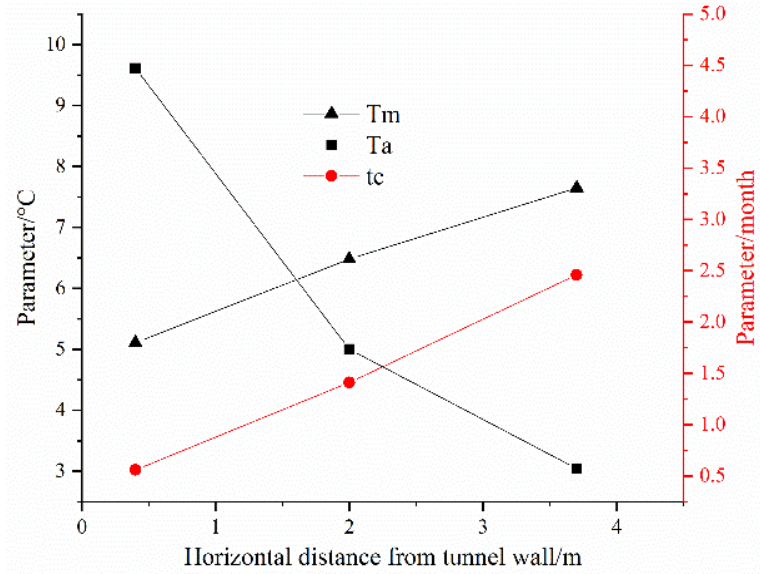

(c)

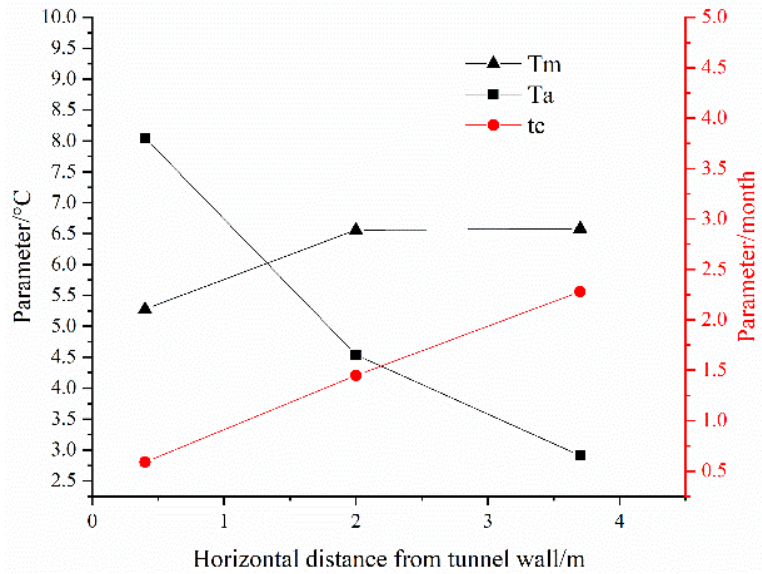

(d)

Figure 8. Fitting parameter: (a) ML-I; (b) ML-II; (c) ML-III; and (d) ML-IV.

Based on the characteristics of the sine function, $T_{m}+T_{a}$ represents the annual maximum temperature at the monitoring site and $T_{m}-T_{a}$ for the annual minimum temperature. Figure 9 shows that the trends in the temperature distance measurements were the same for all four lines of measurement in this section. The annual maximum and minimum temperature of the surrounding rock varied curvilinearly with the distance from the tunnel wall and gradually tended toward a stable value. This was consistent with the trend of temperature propagation within the one-dimensional cylindrical cavern wall.

According to this trend, we chose the appropriate formula temperature distance curve for fitting.

$$
T=T_{0}+\alpha e^{-\frac{x}{\theta}}
$$

where $T$ is the annual maximum or minimum temperature at a point within the surrounding rock, $T_{0}$ is the stable value at infinite distances, $\alpha$ and $\theta$ are constant parameters, and $x$ is the horizontal distance from the tunnel wall.

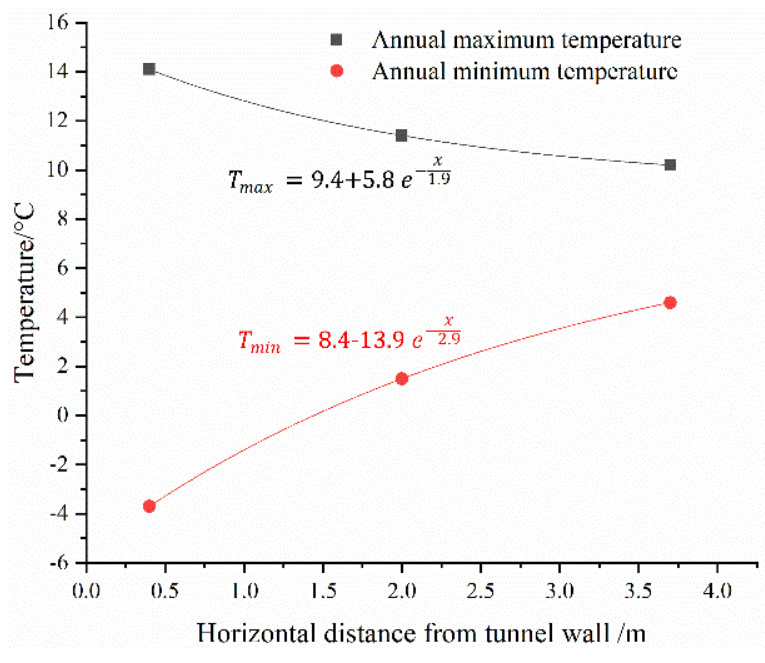

(a)

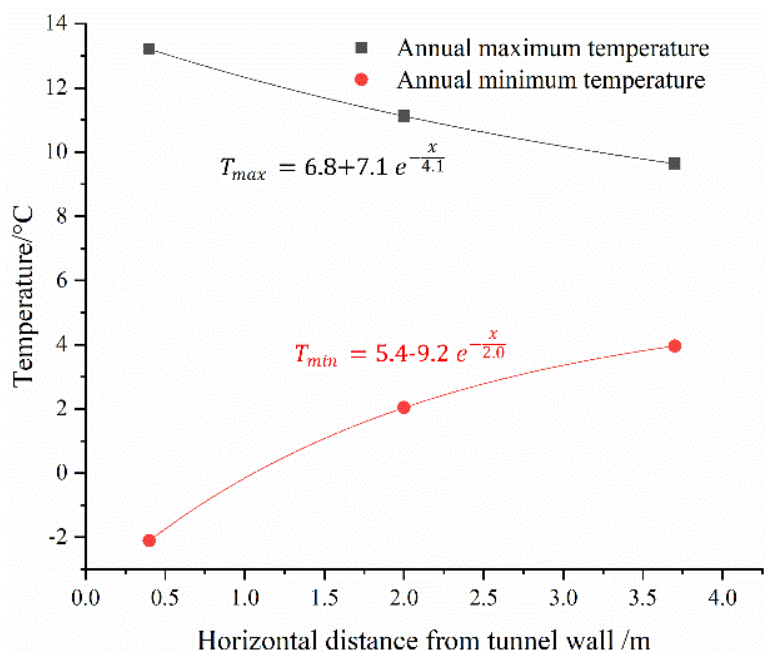

(b)

Figure 9. Cont. 


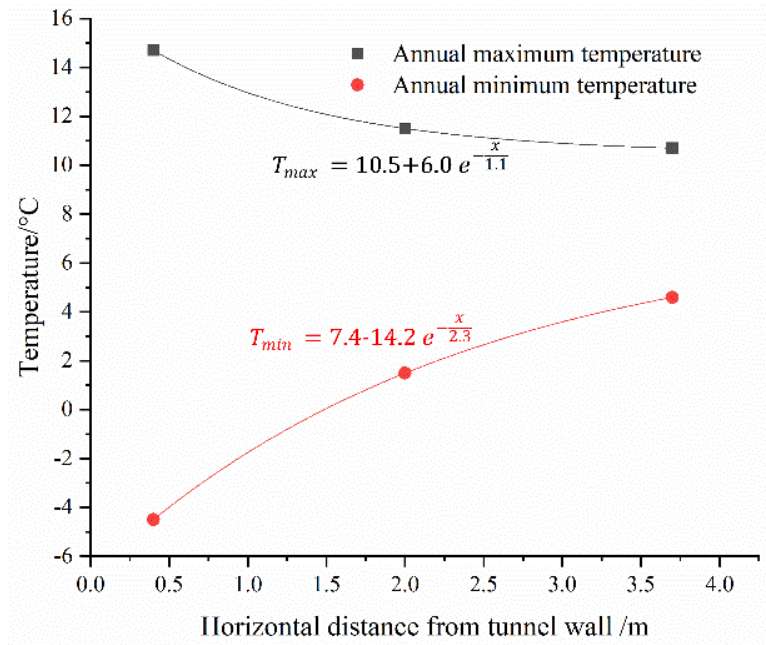

(c)

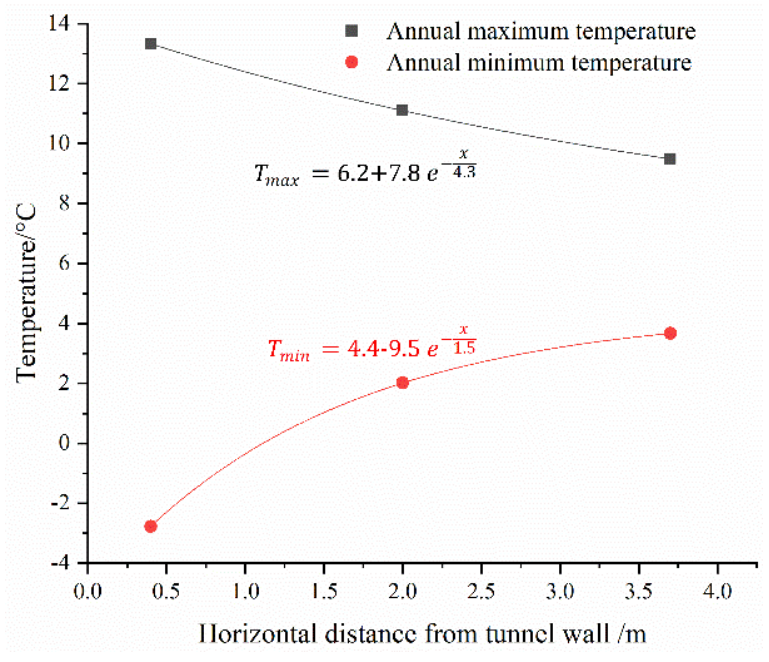

(d)

Figure 9. The annual maximum and minimum temperatures: (a) ML-I; (b) ML-II; (c) ML-III; and (d) ML-IV.

As the distance from the tunnel wall increased, the annual maximum temperature of the surrounding rock decreased, and the annual minimum temperature increased. The fitting results revealed that $T_{0}$ varied among the measuring lines. The results of the curve fitting showed that the annual maximum temperature of the surrounding rock on the left side of the tunnel was greater than that on the right side, and the annual minimum temperature was lower than that on the left side, with a difference of 0.6 to $1^{\circ} \mathrm{C}$. However, the difference in temperature on the same side is not significant. This indicates that the temperature distribution in the surrounding rock in this section was not symmetrical along the central axis of the tunnel.

\subsection{Monitoring Results of Section $2($ RK315 + 710)}

\subsubsection{Temperature Changes in the Short-Term after Excavation}

Figure 10 demonstrates that the temperature variations in Section 2 were completely different from those in Section 1. The temperature of the surrounding rock in Section 2 mainly experienced three major temperature fluctuations, which were caused by the onsite construction.

After the excavation of section RK315 + 710, the blasting generated heat that caused the temperature at monitoring point 4 to reach $19.8^{\circ} \mathrm{C}$ on 8 May 2015, while the temperature at deeper monitoring points 5 and 6 remained normal. The heat of hydration generated by the shotcrete caused a rapid increase in the temperature of the surrounding rock within the monitored area after 9 May. As shown in Table 1, the magnitude of the temperature increased and then decreased with increasing distance from the tunnel wall and the time to reach the extreme value was delayed accordingly. After the temperature of each monitoring point reached the extreme value, the temperature transitioned smoothly after a continuous decrease in temperature. 


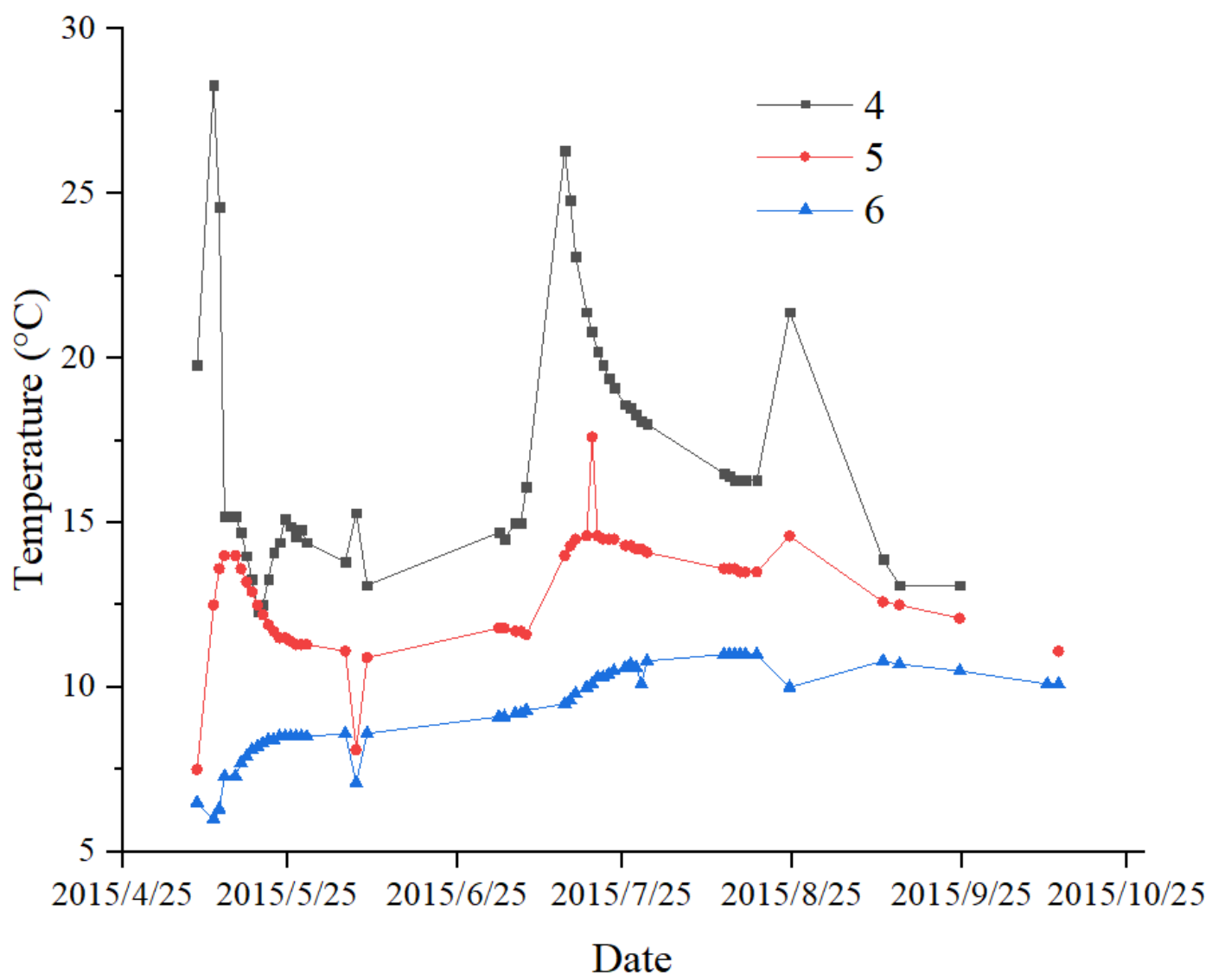

Figure 10. Short-term temperature variation curve with time.

Table 1. Temperature extremes and times of monitoring points.

\begin{tabular}{ccccccc}
\hline $\begin{array}{c}\text { Monitoring } \\
\text { Point }\end{array}$ & $\begin{array}{c}\text { Time to First } \\
\text { Extremum }\end{array}$ & $\begin{array}{c}\text { First Extreme } \\
\text { Temperature } /{ }^{\circ} \mathbf{C}\end{array}$ & $\begin{array}{c}\text { Time to the Second } \\
\text { Extremum }\end{array}$ & $\begin{array}{c}\text { Second Extreme } \\
\text { Temperature } /{ }^{\circ} \mathbf{C}\end{array}$ & $\begin{array}{c}\text { Time to the } \\
\text { Third Extremum }\end{array}$ & $\begin{array}{c}\text { Third Extreme } \\
\text { Temperature } /{ }^{\circ} \mathbf{C}\end{array}$ \\
\hline $2-4$ & 12 May & 28.3 & 15 July & 26.3 & 25 August & 21.4 \\
$2-5$ & 14 May & 14 & $20 \mathrm{July}$ & 17.6 & 25 August & 14.6 \\
$2-6$ & 22 May & 8.4 & None & None & None & None \\
\hline
\end{tabular}

Excavation to the lower step of this section and shotcrete was conducted on 2 July, and the second lining was applied on 9 July. The explosion heat produced by the excavation of the lower steps caused the temperature of monitoring point 4 to increase by $1.6^{\circ} \mathrm{C}$ and then slowly increase. Due to the insulation of the primary lining, monitoring point 4 reached its extreme value only on the 6th day after the construction of the second lining. Because of the greater thickness of the secondary lining, the heat of hydration generated was greater and took longer to dissipate. Despite the barrier of the primary lining and geotextile, the extreme temperature at monitoring point 4 still reached $26.3^{\circ} \mathrm{C}$. The heat of hydration caused by the cement during post-decoration in the tunnel resulted in the temperature of the surrounding rock to rise to a third extreme when the tunnel was at breakthrough However, with the insulation of the second lining, primary lining, and geotextiles, the temperature change in the surrounding rock was less than the previous two times.

At $4 \mathrm{~m}$ from the tunnel wall, the temperature of the surrounding rock was less affected by external influences, and there was a slow transition rather than a clear extreme point. Overall, the heat from the blasting of the tunnel excavation, the hydration heat of the primary and secondary linings, and the hydration heat of the decorative tunnel concrete raised the temperature of the surrounding rock within $4 \mathrm{~m}$ in the short-term. 


\subsubsection{Temperature Change in the Long-Term}

We monitored the LK315 + 710 transect for 14 months from May 2015 to June 2016. The monthly mean temperature at each monitoring point and the same that fitted according to Equation (1) are also plotted in Figure 11.

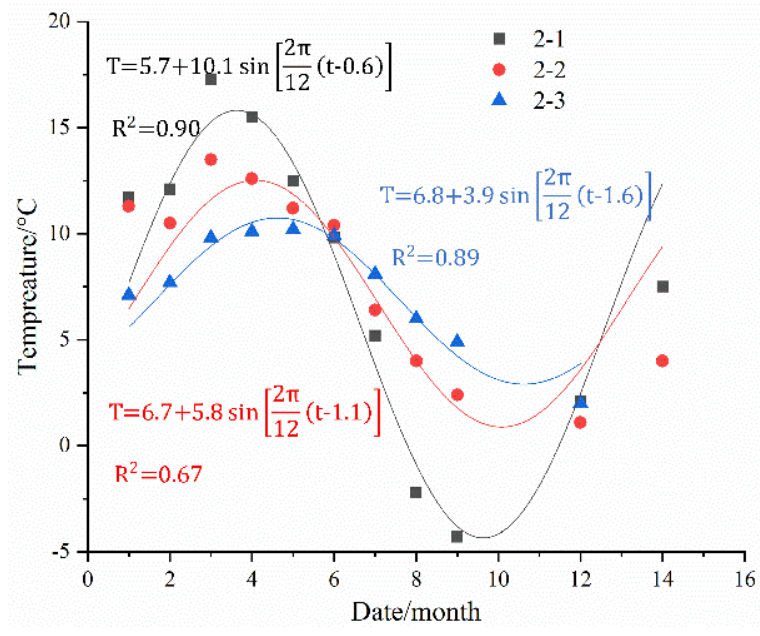

(a)

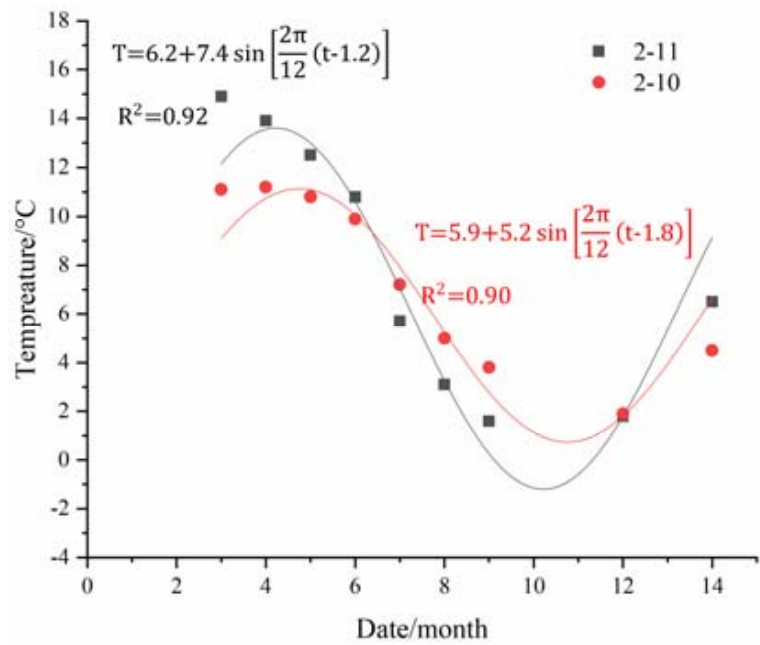

(c)

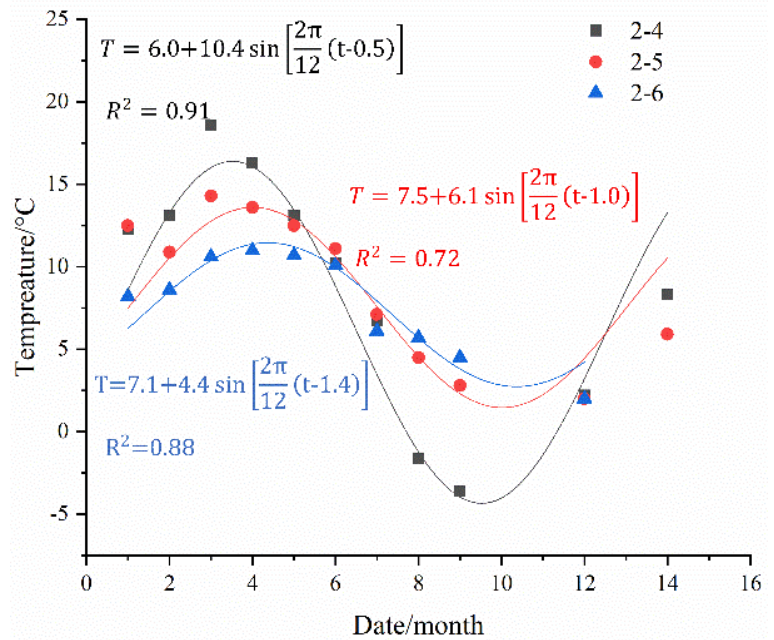

(b)

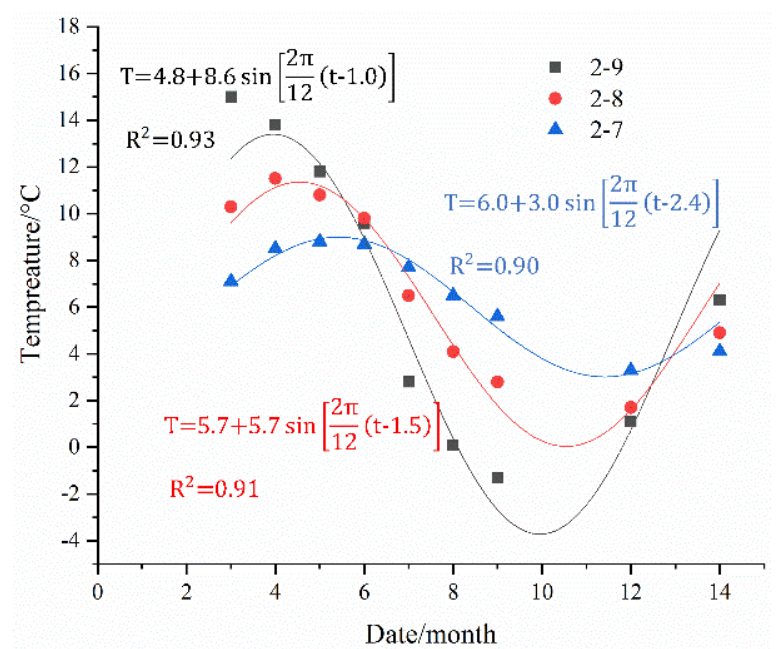

(d)

Figure 11. Temperature time curves at monitoring points in section LK315 + 710: (a) ML-I; (b) ML-II; (c) ML-III; and (d) ML-IV.

As presented in Figure 11, the temperature-time curve of each monitoring point was a sine function with a good fitting degree. As the horizontal distance from the tunnel wall increased, the annual maximum temperature of the surrounding rock decreased, while the annual minimum temperature increased, and the time to reach the extreme point was delayed.

In addition, the initial monitored temperatures were all greater than the fitted data, owing to the heat generated by the various construction activities prior to tunnel penetration, which heated the surrounding rock directly or raised the rock temperature by means of elevated air temperatures. 
Figure 12 illustrates the variation of each fitting parameter with the horizontal distance from the tunnel wall. As the horizontal distance increased, the average annual temperature of the surrounding rock increased and the annual temperature amplitude decreased, but the phase difference of the annual variation period became larger.

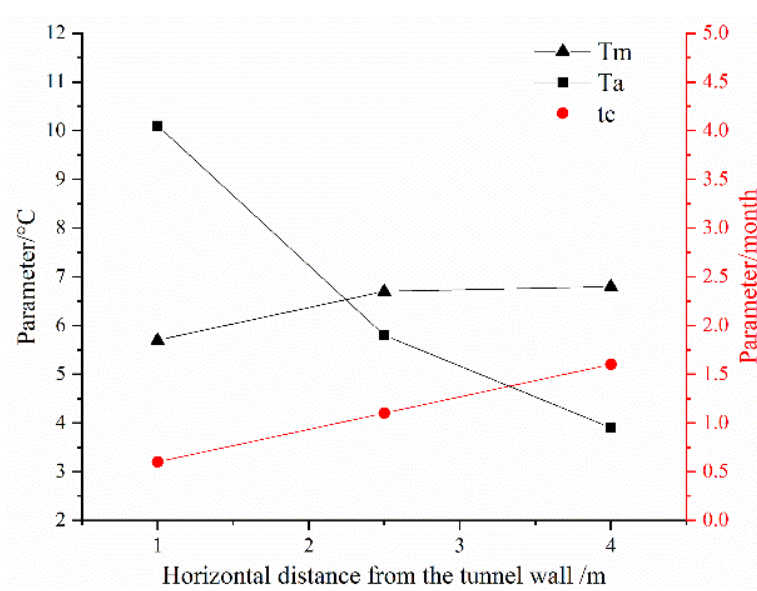

(a)

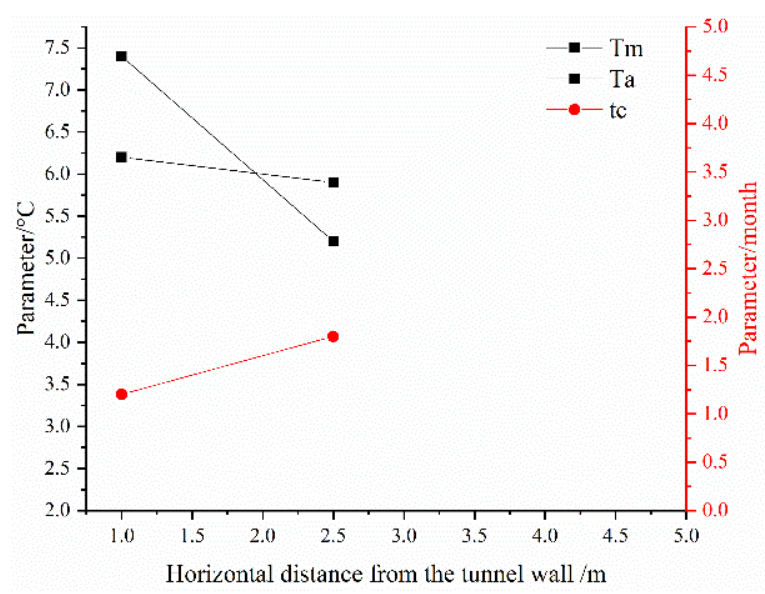

(c)

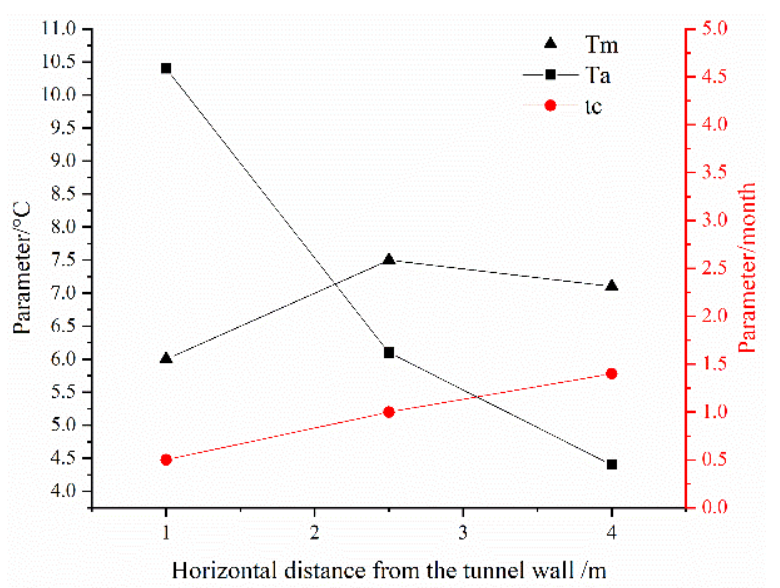

(b)

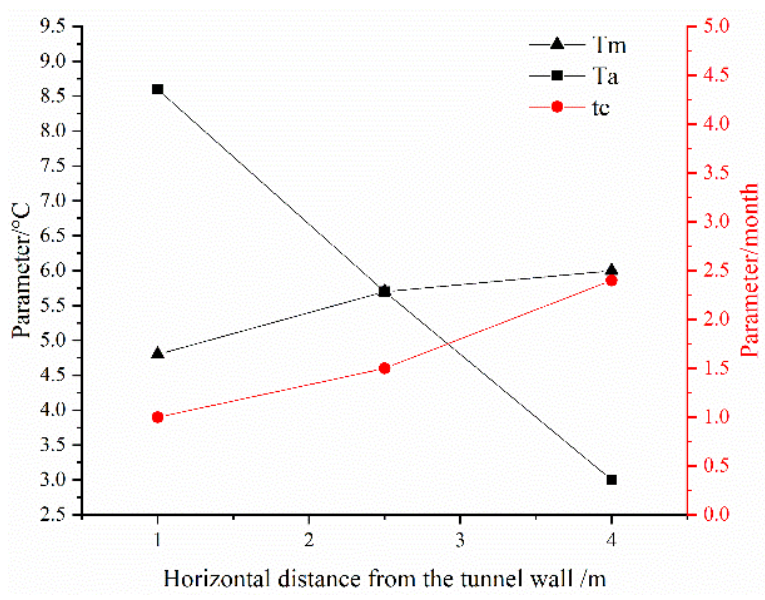

(d)

Figure 12. Fitting parameters: (a) ML-I; (b) ML-II; (c) ML-III; and (d) ML-IV.

Figure 13 shows that the trend in temperature distance measurements was the same for all four lines of measurement in this section. The annual maximum and minimum temperatures of the surrounding rock varied curvilinearly with the distance from the tunnel wall and gradually tended toward a stable value. As depicted in Figure 13, the annual maximum temperature tended to have a higher stable value for the upper step on the left side of the tunnel than on the right side, and the annual minimum temperature was less than on the right side. In contrast, the trend for the lower steps of the tunnel was approximately opposite. 


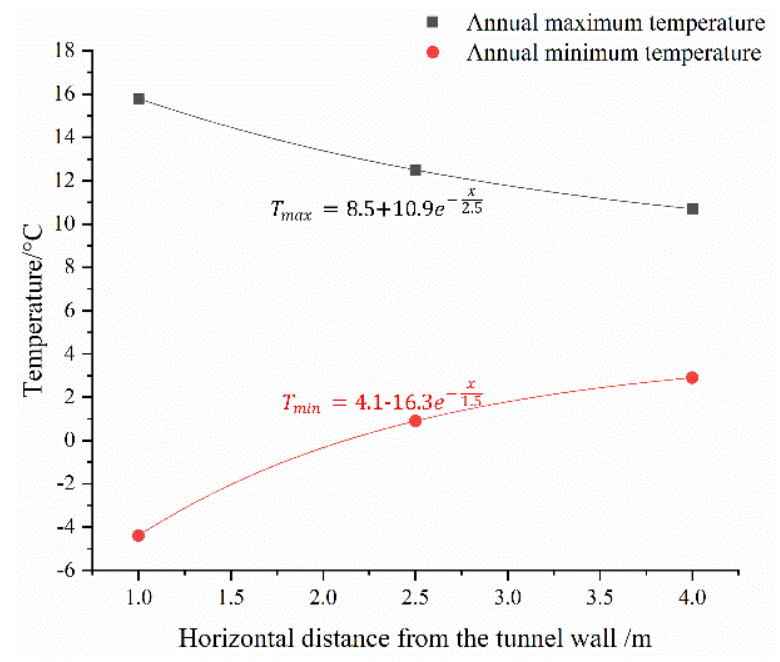

(a)

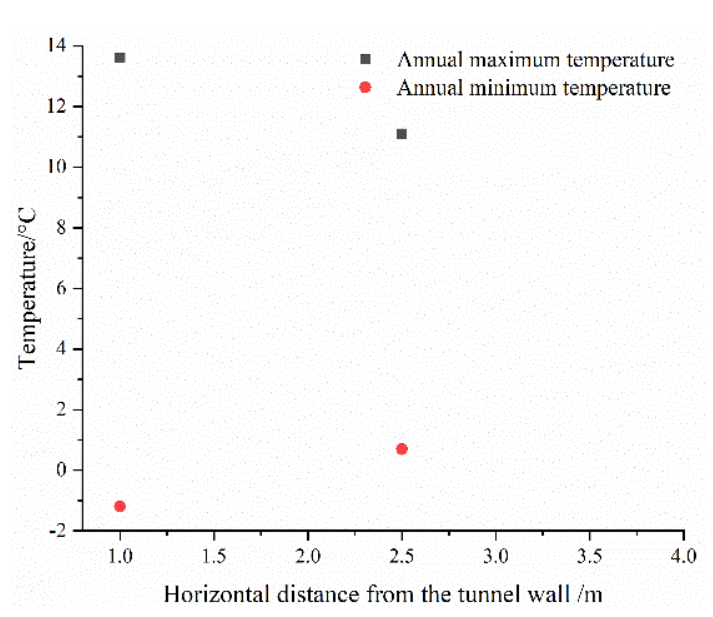

(c)

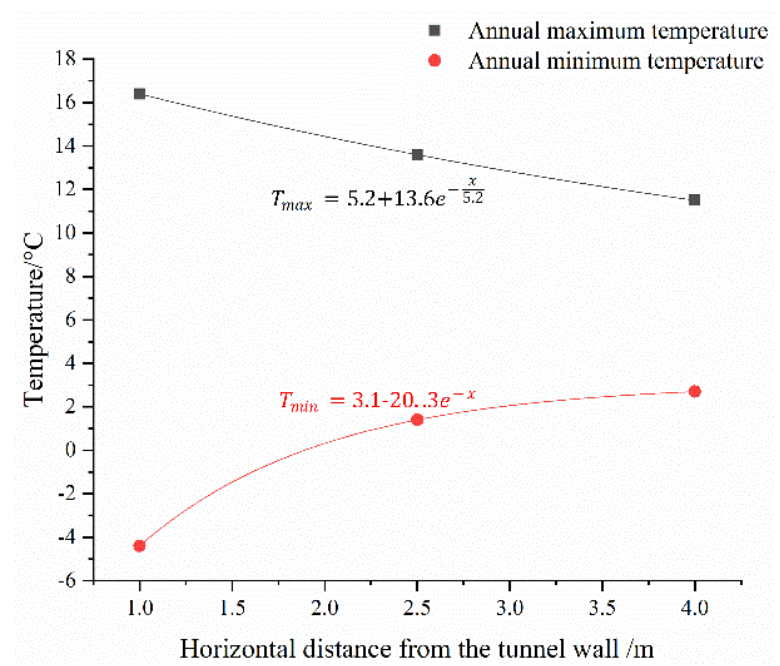

(b)

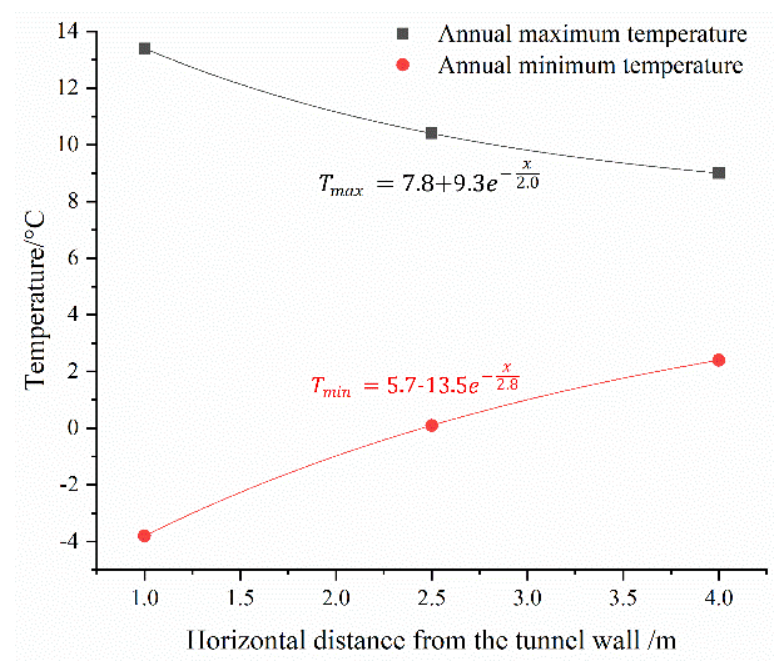

(d)

Figure 13. Curves of the annual maximum and minimum temperatures: (a) ML-I; (b) ML-II; (c) ML-III; and (d) ML-IV.

\section{Discussion}

\subsection{Frozen Depth}

Based on the variations in the annual minimum temperature in the tunnel with the horizontal distance from the tunnel wall, we roughly estimated the location of the annual minimum temperature at $0{ }^{\circ} \mathrm{C}$. It was also possible to determine the extent to which the current section was subjected to tunnel frost damage.

Figure 14 illustrates that the freezing depth distribution pattern was essentially the same in both sections. The freezing depths on the same side of the tunnel were close, but the freezing depth on the left side was greater than that on the right side. In addition, the freezing depth of the upper measurement line was generally smaller than the freezing depth of the lower measurement line since cold air is at the bottom and hot air is at the top, which is consistent with the phenomenon observed in a previous study [6]. The freezing depth in Section 2 is greater than that of Section 1 due to the closer proximity of Section 2 to the cavern entrance. 


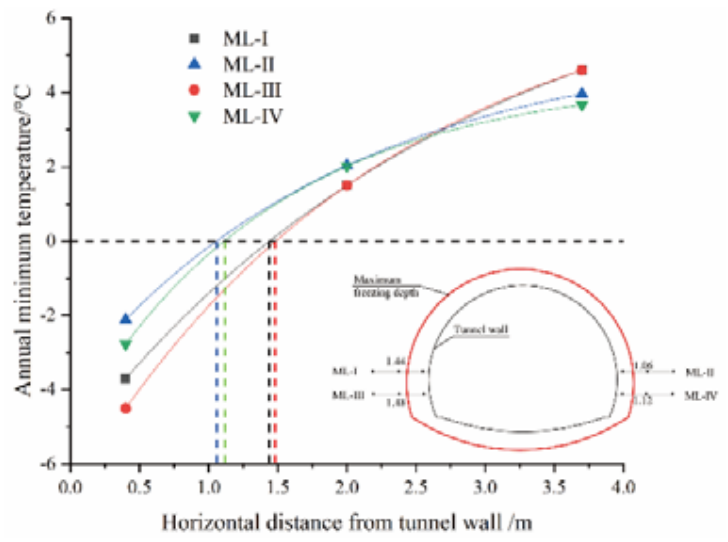

(a)

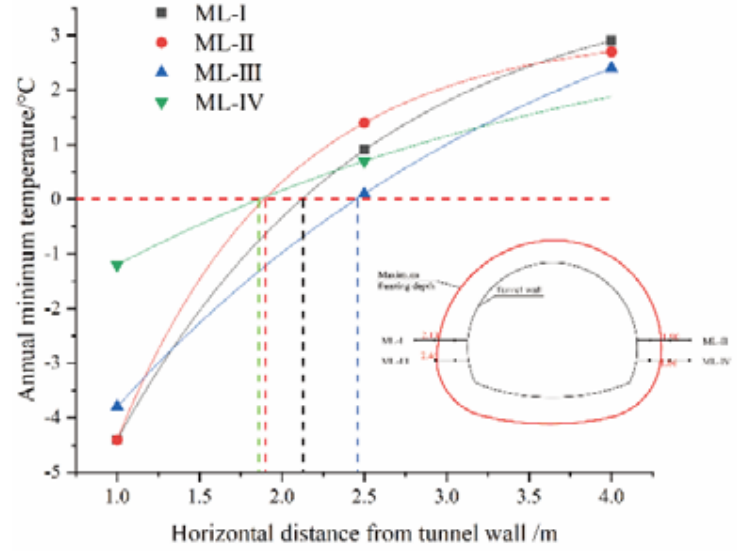

(b)

Figure 14. Frozen depth: (a) Section 1 and (b) Section 2.

\subsection{Asymmetric Temperature Fields}

The temperature distribution of the monitoring points on the two measurement lines symmetrical about the center line on both sides of the tunnel was not symmetrical along the center line of the tunnel. The results of the tunnel monitoring and fitting of the monitoring data were used to analyze the degree of asymmetry in the temperature distribution at each section.

As shown in Figure 15a, there was a significant difference in the annual maximum temperature between the two sides of the section, with a difference of $0.3 \sim 0.9{ }^{\circ} \mathrm{C}$, and a difference in the annual minimum temperature of $0.5 \sim 1.6{ }^{\circ} \mathrm{C}$.

As shown in Figure 15b, the annual mean temperatures $\left(T_{m}\right)$ of the surrounding rock on both sides of the tunnel were approximately the same, with a significant difference of only $3.7 \mathrm{~m}$. In the meantime, the annual temperature variations $\left(T_{a}\right)$ on both sides of the surrounding rock differed visibly, and this disparity decreased with increasing distance from the tunnel. The large gap between the recommended annual maximum and minimum temperatures was on account of the differences in the annual variation of temperature in the surrounding rock on both sides.

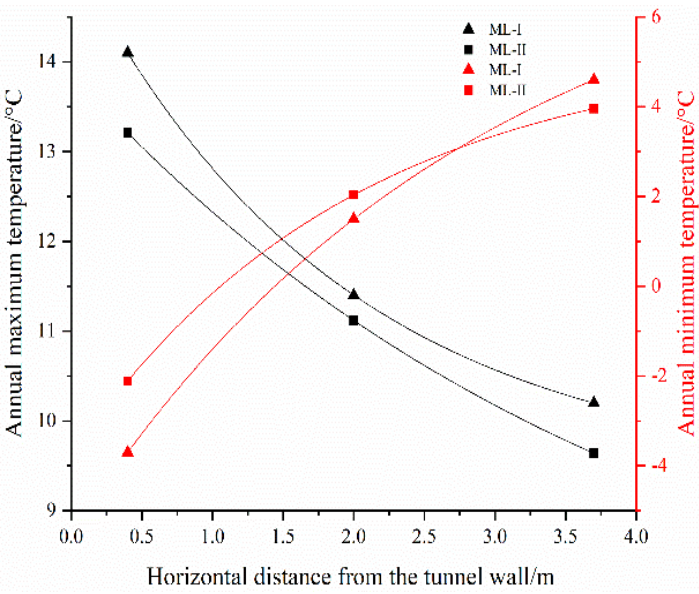

(a)

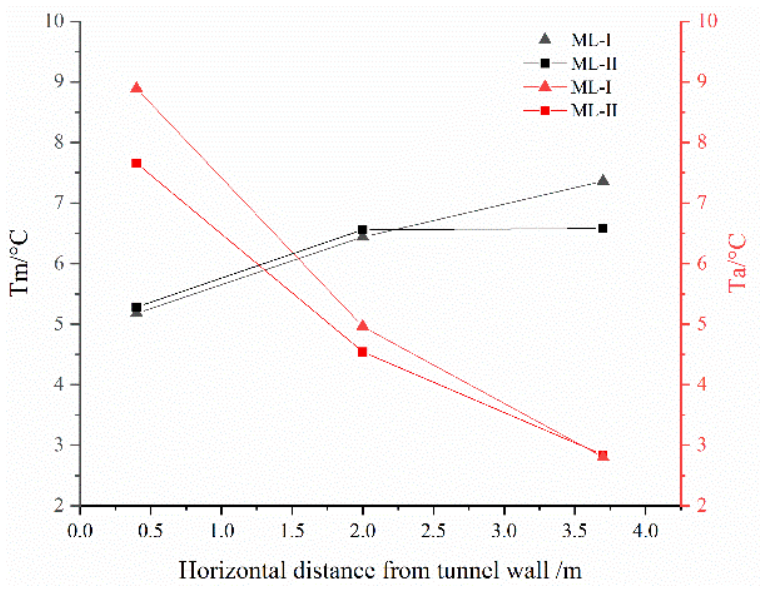

(b)

Figure 15. Cont. 


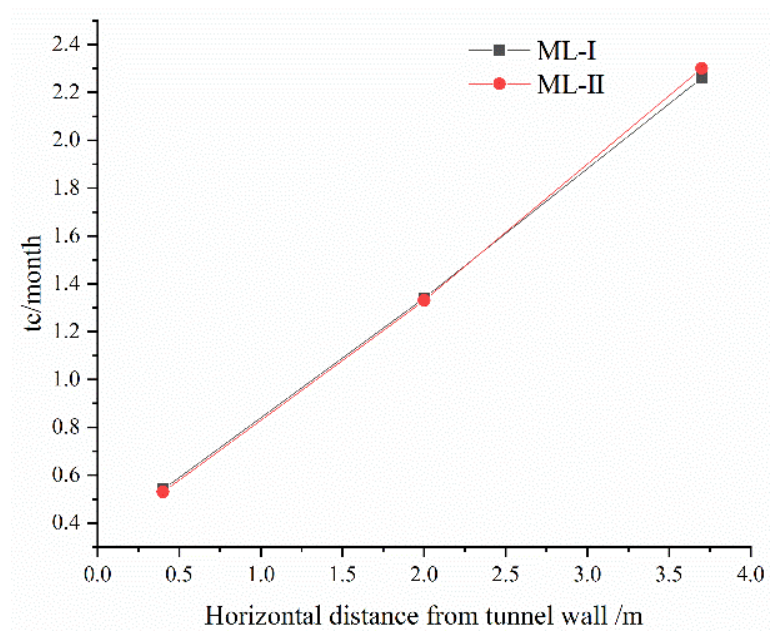

(c)

Figure 15. Temperature distribution of Section 1: (a) maximum and minimum temperatures; (b) $T_{m}$ and $T_{a} ;$ and (c) $t_{c}$.

As shown in Figure 15c, the $t_{c}$ of the surrounding rock on both sides was essentially the same.

The depth of burial in this section of the tunnel was $42.7 \mathrm{~m}$, which is a deeply buried tunnel. The temperature of the surrounding rock on both sides of this tunnel section had, in principle, been unaffected by the fluctuations in the temperature outside the ground surface. Moreover, the $t_{c}$ and annual average temperatures of the surrounding rock on both sides were essentially identical. The difference in temperature between the two sides of this section is therefore attributable to the annual temperature amplitude. Given the presence of 1-2 $\mathrm{m}$ thick, softer gneiss in the section, the difference in thermal conductivity between the gneiss and granitic gneiss may be responsible for the difference in temperature between the two sides.

As shown in Figure 16a, there was a large difference between the annual maximum temperatures of the measured lines on both sides of this section. The value of ML-II on the deep buried side was greater than the temperature of ML-I on the shallow buried side, with the difference ranging from 0.6 to $1.1^{\circ} \mathrm{C}$. However, the difference in annual minimum temperatures was not substantial.

We found that the annual temperature variation $T_{a}$ varied more consistently (difference of 0.3 to $0.5^{\circ} \mathrm{C}$ ) for the two lines of measurement from Figure 16b. The value of ML-II on the deep buried side was greater than that of ML-I on the shallow buried side. However, the mean annual temperature $\left(T_{m}\right)$ varied more, with a gap of $0.3 / 0.8^{\circ} \mathrm{C}$. The addition and subtraction of annual temperature variations and annual average temperatures ultimately results in large differences in annual maximum temperatures.

As indicated in the Figure $16 c$, the $t_{c}$ of the survey line ML-I was greater than that of ML-II, with a difference of $0.1 / 0.2$ months, which indicates that the temperature change on the shallow buried side occurred later than that on the deep buried side.

The signature of the temperature field that appears above was related to the sloping ground surface above the tunnel. The initial temperature field before the tunnel excavation would be roughly inclined with the slope of the terrain, which resulted in the temperature on the deep buried side to be generally higher than that on the shallow buried side for the same horizontal height case. This explains the greater $T_{m}$ on the deep buried side. Concurrently, under the influence of cold air, the temperature difference between the surrounding rock and air temperature was greater on the deep buried side, an equilibrium was reached earlier, and its variation was greater. This explains the larger $T_{a}$ and smaller $t_{c}$ on the deep buried side. 


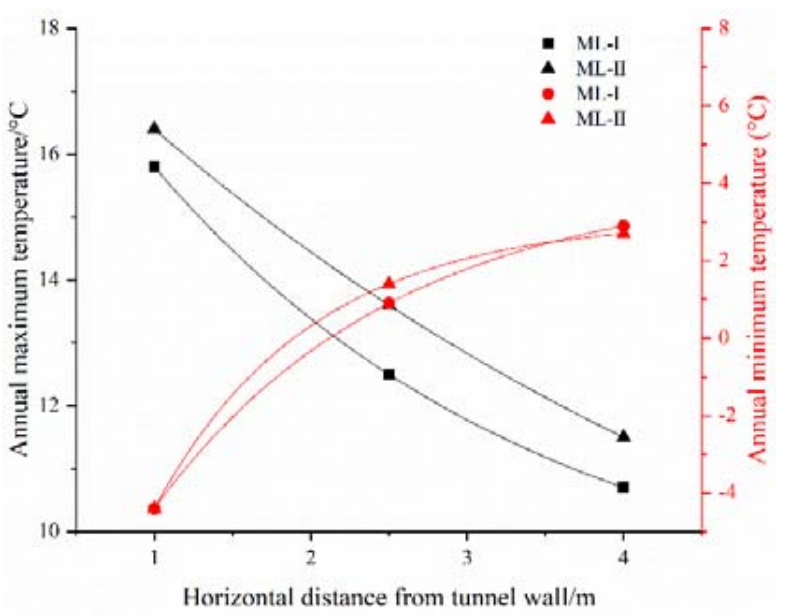

(a)

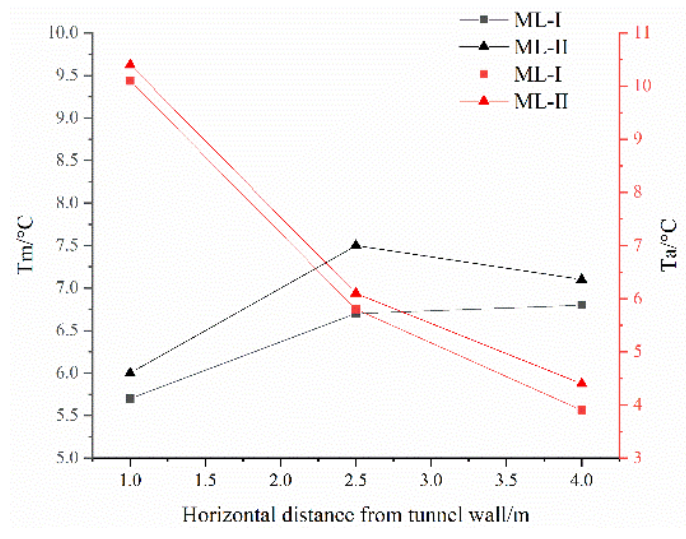

(b)

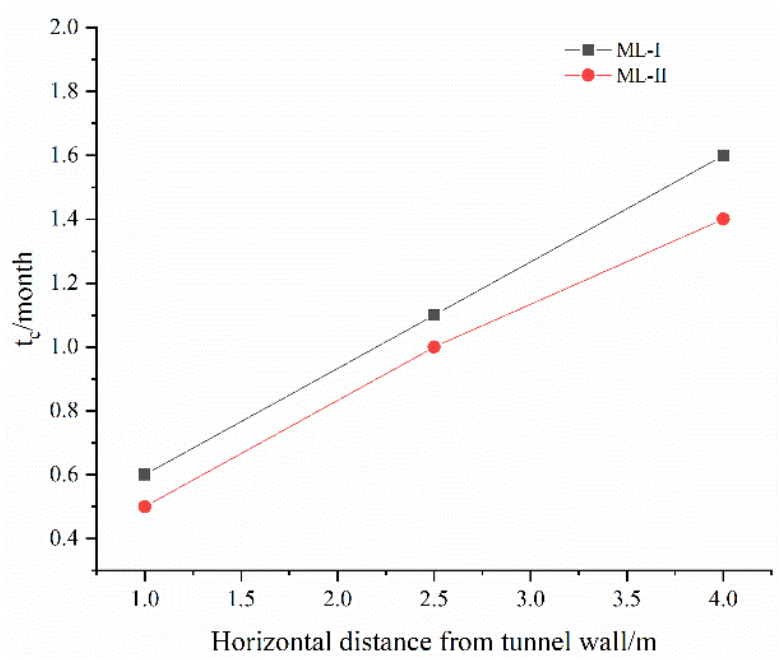

(c)

Figure 16. Temperature distribution of Section 2: (a) maximum and minimum temperatures; (b) $T_{m}$ and $T_{a}$; and (c) $t_{c}$.

\section{Conclusions}

In order to study the distribution characteristics of temperature in topographically biased tunnels, temperature monitoring was conducted for 14 months for this research. The temperature in the short-term after tunnel excavation was analyzed. The annual mean temperature was fitted by means of a sine function and the variation of its fitted parameters was analyzed, leading to the following conclusions.

(1) The blasting of the rock, the initial lining, the second lining, and the hydration of the concrete for later decoration generated a large amount of heat, causing the temperature of the surrounding rock within $4 \mathrm{~m}$ to change dramatically in a short period of time;

(2) The temperature of the surrounding rock on both sides of the tunnel varied in a sinusoidal curve after excavation. As the distance from the tunnel wall increased, the annual average temperature of the surrounding rock elevated, the amplitude decreased, and the delay time increased. Meanwhile, the annual maximum temperature decreased and the annual minimum temperature increased; 
(3) On the basis of the annual minimum temperature versus distance from the cavern wall, the maximum freezing depth for each section was roughly determined. The differences in freezing depth between the same sides of the tunnel were small, but the distribution of freezing depth in the tunnel was not symmetrical about the axis;

(4) All of the sections monitored in this paper exhibited an asymmetric distribution of temperature with different origins. According to the temperature fitting equation, the asymmetric distribution of temperature in the surrounding rock of Section 1 was driven by large differences in the magnitude of annual variation, and it is speculated that the difference was in thermal conductivity between the weak gneiss and granite gneiss locally present in the section. In contrast, the asymmetric distribution of temperature in Section 2 was influenced by topographic deviations;

(5) The distance from the tunnel portal was an important factor that mainly affected the temperature of the surrounding rock. The greater the distance from the tunnel portal, the smaller the maximum freezing depth of the section, the lower the annual maximum temperature, and the higher the annual minimum temperature.

Author Contributions: Methodology, L.N. and M.Z.; software, X.R.; formal analysis, Y.W.; investigation, C.D., S.D. and T.Z.; resources, Y.X.; data curation, Y.H.; writing-original draft preparation, T.Z.; writing-review and editing, M.Z.; supervision, L.N.; project administration, S.D.; funding acquisition, L.N. All authors have read and agreed to the published version of the manuscript.

Funding: This research was funded by the National Natural Science Foundation (Grant No. 41572254, 41502322, 41702300, and 41502272) and the Science and Technology Development Project of Jilin Province, China (Grant No. 20180520073JH).

Conflicts of Interest: The authors declare no conflict of interest.

\section{References}

1. Xu, Q.; Ding, W.; Zhu, H.; Tang, Z.; Li, Y. Study on progressive unloading failure characteristics of superlarge tunnel in soft and weak rock mass. China Civ. Eng. J. 2017, 50, 104-114.

2. Qu, M.; Xie, Q.; Hu, Y.; Li, C. Model test on frost heaving force of unnel lining in cold region. Chin. J. Rock Mech. Eng. 2015, 34, 1894-1900.

3. Yang, P.; Ke, J.-M.; Wang, J.G.; Chow, Y.K.; Zhu, F.-B. Numerical simulation of frost heave with coupled water freezing, temperature and stress fields in tunnel excavation. Comput. Geotech. 2006, 33, 330-340. [CrossRef]

4. Tang, G.Z.; Wang, X.H. Effect of temperature control on a tunnel in permafrost. Tunn. Undergr. Space Technol. 2007, 22, 483-488. [CrossRef]

5. Roy, K.; Lim, J.B.P.; Lau, H.H.; Yong, P.M.; Clifton, G.C.; Johnston, R.P.D.; Wrzesien, A.; Mei, C.C. Collapse behaviour of a fire engineering designed single-storey cold-formed steel building in severe fires. Thin-Walled Struct. 2019, 142, 340-357. [CrossRef]

6. Zhao, P.; Chen, J.; Luo, Y.; Li, Y.; Chen, L.; Wang, C.; Hu, T. Field measurement of air temperature in a cold region tunnel in northeast China. Cold Reg. Sci. Technol. 2020, 171, 102957. [CrossRef]

7. Girard, L.; Gruber, S.; Weber, S.; Beutel, J. Environmental controls of frost cracking revealed through in situ acoustic emission measurements in steep bedrock. Geophys. Res. Lett. 2013, 40, 1748-1753. [CrossRef]

8. Kozlowski, T. A semi-empirical model for phase composition of water in clay-water systems. Cold Reg. Sci. Technol. 2007, 49, 226-236. [CrossRef]

9. Fei, T.; Antonio, B. Effect of temperature on deep lined circular tunnels in transversely anisotropic elastic rock. Undergr. Space 2016, 1, 79-93. [CrossRef]

10. Zhou, Y.; Zhang, X.; Deng, J. A mathematical optimization model of insulation layer's parameters in seasonally frozen tunnel engineering. Cold Reg. Sci. Technol. 2014, 101, 73-80. [CrossRef]

11. Cui, S.a.; Liu, P.; Li, Z.; Xu, X.; Ju, J.W. Shotcrete performance-loss due to seepage and temperature coupling in cold-region tunnels. Constr. Build. Mater. 2020, 246, 118488. [CrossRef]

12. He, X.; Li, A.; Ning, Y. Optimization of outdoor design temperature for summer ventilation for undersea road tunnel using field measurement and statistics. Build. Environ. 2020, 167, 106457. [CrossRef]

13. Jun, K.-J.; Hwang, Y.-C.; Yune, C.-Y. Field measurement of temperature inside tunnel in winter in Gangwon, Korea. Cold Reg. Sci. Technol. 2017, 143, 32-42. [CrossRef]

14. Zhang, Y.; Li, X. Heat transfer formalism using GFM and FEM in underground tunnels. Build. Environ. 2018, 143, 717-726. [CrossRef]

15. Lyu, Z.; Xia, C.; Liu, W. Analytical solution of frost heaving force and stress distribution in cold region tunnels under nonaxisymmetric stress and transversely isotropic frost heave of surrounding rock. Cold Reg. Sci. Technol. 2020, 178, 103117. [CrossRef] 
16. Zhang, X.; Lai, Y.; Yu, W.; Zhang, S. Numerical analysis for the three-dimension temperature fields in cold region tunnels. J. China Railw. Soc. 2003, 25, 84-90.

17. Tan, X.; Chen, W.; Yang, D.; Dai, Y.; Wu, G.; Yang, J.; Yu, H.; Tian, H.; Zhao, W. Study on the influence of airflow on the temperature of the surrounding rock in a cold region tunnel and its application to insulation layer design. Appl. Therm. Eng. 2014, 67, 320-334. [CrossRef]

18. Zhang, X.; Zhou, Z.; Li, J.; Zhou, Y.; Han, F. A physical model experiment for investigating into temperature redistribution in surrounding rock of permafrost tunnel. Cold Reg. Sci. Technol. 2018, 151, 47-52. [CrossRef]

19. Zeng, Y.; Liu, K.; Zhou, X.; Fan, L. Tunnel temperature fields analysis under the couple effect of convection-conduction in cold regions. Appl. Therm. Eng. 2017, 120, 378-392. [CrossRef]

20. Liu, W.; Feng, Q.; Wang, C.; Lu, C.; Xu, Z.; Li, W. Analytical solution for three-dimensional radial heat transfer in a cold-region tunnel. Cold Reg. Sci. Technol. 2019, 164, 102787. [CrossRef]

21. Feng, Q.; Jiang, B.-S.; Zhang, Q.; Wang, G. Reliability research on the 5-cm-thick insulation layer used in the Yuximolegai tunnel based on a physical model test. Cold Reg. Sci. Technol. 2016, 124, 54-66. [CrossRef]

22. Xu, P.; Wu, Y.; Wang, Z.; Huang, L. Distribution laws of freeze-thaw cycles and unsaturated concrete experiments in cold-region tunnels. Cold Reg. Sci. Technol. 2020, 172, 102985. [CrossRef] 